This item was submitted to Loughborough's Research Repository by the author.

Items in Figshare are protected by copyright, with all rights reserved, unless otherwise indicated.

\title{
A framework for understanding user requirements for an information service : defining the needs of informal carers
}

PLEASE CITE THE PUBLISHED VERSION

PUBLISHER

(c) American Society for Information Science and Technology / published by John Wiley \& Sons

LICENCE

CC BY-NC-ND 4.0

REPOSITORY RECORD

Hepworth, Mark. 2019. "A Framework for Understanding User Requirements for an Information Service :

Defining the Needs of Informal Carers". figshare. https://hdl.handle.net/2134/3727. 
This item was submitted to Loughborough's Institutional Repository (https://dspace.lboro.ac.uk/) by the author and is made available under the following Creative Commons Licence conditions.

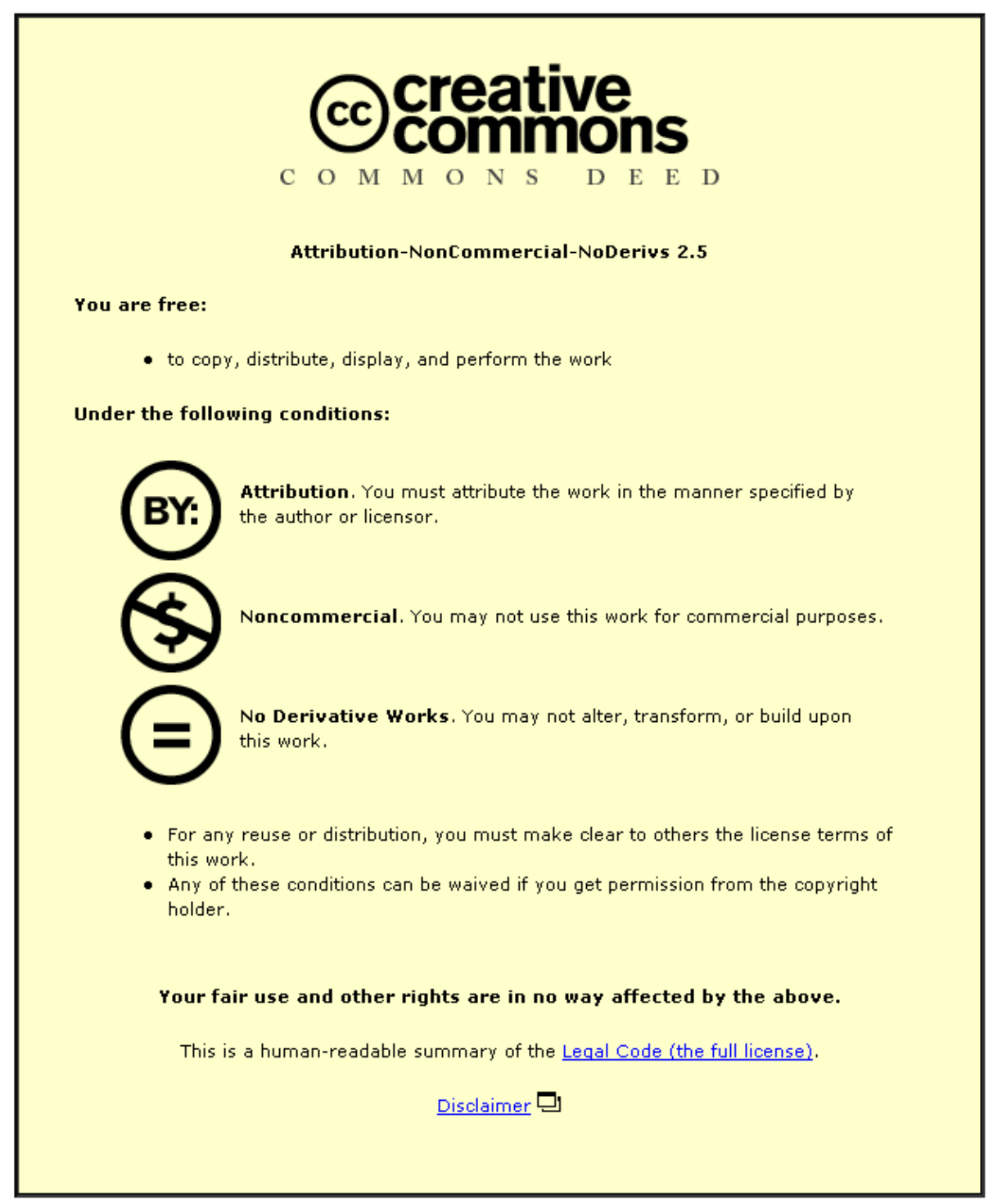

For the full text of this licence, please go to: http://creativecommons.org/licenses/by-nc-nd/2.5/ 


\title{
A framework for understanding user requirements for an information service: defining the needs of informal carers
}

\author{
Mark Hepworth \\ Department of Information Science \\ Loughborough University \\ Leicestershire
}

LE11 3TU

United Kingdom

e-mail: M.Hepworth@lboro.ac.uk

\begin{abstract}
The aim of this research was to develop a conceptual framework that would help to collect and understand the information needs of a target community. Many information behaviour frameworks already exist, however; although they share some features, they tend to focus on different aspects of the person and their interaction with information. It was proposed that a synthesis of these frameworks could lead to a comprehensive framework. Previous research was analysed and an initial framework defined. This was piloted and adapted and then applied to data on informal carers. This led to further adaptation. Informal carers are people who care for another person, generally a relative, for more than fourteen hours per week and are not paid for this. The data stemmed from
\end{abstract}


sixty interviews that were transcribed and coded. This paper presents the data on informal carers and their information experience using the final framework. This serves to demonstrate how the framework sensitizes the researcher to certain types of significant data, enables the organization of the data, indicates the relationships between different types of data and, overall, helps to provide a rich picture of the target community's information needs. In conclusion the paper discusses the differences and advantages of the framework in relation to previous work and also the limitations of the study and possible further research.

\section{Introduction}

The aim of this research was to develop a framework that would help to identify key aspects of the person, their social environment and their interaction with sources of information (people or artifacts) that would facilitate the specification of user requirements for an information service. This could then feed into the still active discussion among system designers and software engineers about how to capture user requirements (Patmore et al. 2003) as well as user needs studies by information service/product providers.

Numerous models of information behaviour and the interacting variables have evolved over the years. Several of these are described by Case (2002) and Wilson (1999). Vakkari has also provided an overview of issues of concern to researchers of information seeking; particularly those interested in the impact of task complexity (Vakkari, 1998). The models that have received wide dissemination include Krikelas (1983), Ellis (1989), 
Belkin et al. (1995), Marchionini (1995), Kuhlthau (1991), Sarcevic (1996), Ingwersen (1996), Leckie et al.(1996), Hert (1997), Spink (1997), Wilson (1999) and Nicholas (2000). Individual models identify similar variables as well as highlighting different aspects of information behaviour and the information seeking environment. Different models are also applied at different levels of abstraction. For example authors coming from an information retrieval background, such as Saracevic (1996) or Spink (1997), tend to concentrate on the moment of interaction with information and the system, whereas authors such as Leckie et al. (1996) place more emphasis on the wider (work) context. It was therefore felt that there was an opportunity to synthesise, adapt and build on these models and apply the resulting construct to data on specific communities. This research would therefore help to answer the following questions:

- What factors or variables have previous authors identified as important in terms of their affect on information behaviour?

- Are there common variables and can variables be synthesised and categorised under common broad categories of data?

- Does this result in a framework that can be used to analyse and organize data on the information experience of target communities?

- Does the result of the analysis of this data lead to a rich picture of the information experience of the target community and help to identify possible information solutions?

- Does the resulting framework build on previous frameworks either in terms of its applicability to real life situations, its inclusive nature, its cohesiveness and its ability to generate questions for further research? 


\section{Literature review}

The following literature review serves two purposes, including, clarifying the context within which this research took place and identifying broad categories of data that previous authors have considered significant for understanding the information experience of people and their needs. The latter feeds into the design of the initial framework that was applied to a study of the information experience of post-graduate Information Studies’ students, adapted and later applied and further adapted during the study of informal carers. It should be noted that the following is a distilled version of the original review (Hepworth, 2002). The following review, however, serves the purpose of clarifying the context and identifying broad categories of data.

Previous authors have highlighted the importance of roles, associated norms and tasks, which, to some extent, create the information need. Ingwersen mentions the significance of 'work', 'task', 'goals' (1996); Saracevic, (1996), mentions 'situations' and 'task', Marchionini, (1995), 'tasks’, 'components (time, costs)', Leckie et al. (1996) refers to 'work roles' and 'tasks' as the primary drivers for seeking. Hert, (1997), notes 'orgnisational setting', 'roles', 'project', 'tasks', Wilson, (1999), notes the significance of 'person in context', 'role related', 'environment' factors. Norms are not an area that tends to be discussed in terms of information provision. Solomon (1997), however, does recognise the significance of norms. Nicholas (2000) also recognises the importance of norms, although he does not use the term norms, in that he notes that different occupations will place different values on source characteristics such as quality or 
currency. Belkin (1994) also noted how the characteristics of texts (source character) may be relevant in different situations which again implies that normative values and expectations affect information interaction.

Another area that authors consider important is the source and the character of sources (Line, 1971, Wilson et al. 1979, Choo 1994). This has been the traditional focus of user studies in library science - identifying which sources (such as books or e-serials) people use and want. Such data gives the information provider an indication of the content that the user or potential user wants in the 'collection'. Past frameworks and models tend to assume that sources are either hard-copy (books, journals, articles, pictures etc.) or electronic information sources such as databases or Web sites. The concept of source can also include other sources of information including organisations and individuals. Authors such as Belkin (1994) and Nicholas (2000) have also highlighted the importance of different characteristics of sources and how these may effect information behaviour and make them more likely to relate to the needs of the user. Sources and subject content were therefore identified as an important part of the framework.

From the above research roles, norms and tasks as well as sources and subject content were recognized as significant factors that effect the information experience and for the purpose of this research and the development of the initial conceptual framework (see Figure 1) were given the broad label of environmental data. 
Authors have also highlighted the significance of knowledge and thought processes as well as affective data (feelings) and learning styles and personality data, that is, categories of data that relate to the internal characteristics of the individual. Allen (1991) for example discusses the importance of the knowledge that the individual has of the subject and also the knowledge they have of the information systems they use. Thus distinctions are made between novice and expert user. With regard to thought processes associated with information seeking, use and learning, authors such as Hert (1997) (who lists many ‘cognitive processes’ such as choosing, doubting, revising etc.), Kuhlthau (1997) (increased interest), and Ellis (1989) (differentiating etc.) tend to imply that these processes will always be evident among people when they conduct an information intensive task. Whereas Ingwersen (1996) recognises the transient nature of these processes. It is also likely that specific processes may or may not be present depending on various factors including the role, task, knowledge and source characteristics. Cheuk’s (1997) work supports this view.

Affective data has been of particular interest to Kuhlthau (1991). Kuhlthau highlighted how different emotions may be associated with information seeking behaviour and types of task. Learning style, also referred to as cognitive style, refers to the way people prefer to learn and personal preferences for conceptualising and visualising information. Ford, Wood \& Walsh (1994) have looked into the impact of 'cognitive style' on information behaviour and draw attention to the need to develop information services that relate to the different characteristics of the individual. 
Nicholas (2000) highlights the importance of 'personality' and Hert (1997) refers to 'mood'. Differences have been identified between people who regard their situation as a challenge and are very persistent and proactive in looking for answers and those who do not. Miller and Mangan (1983) and Baker (1995) for example described these as 'monitors' and 'blunters'. Wilson (1999) suggests that characteristics such as selfefficacy (a similar concept to locus of control) and learnt stress coping strategies may be factors that affect the information experience

Authors have therefore identified different categories of data that concern the mental state that have an impact on information interaction. For the purpose of this research and the development of a conceptual framework these were given the broad label of psychological data. Within this broad category, the sub-categories cognitive process, cognitive knowledge, cognitive ability and style and affective were defined.

Historically data gathered on either users or potential users' information seeking behaviour is common. For example data such as inter library loans, the use of citations, online database usage statistics and web logs. Behavioural data is important because it indicates a demand that implies wants and needs as well as preferences for use. Studies that have focused, primarily, on behavioural data, include Line (1971), Wilson et al. (1979), Ellis (1989) and more recently Spink et al. (1998), Spink et al. (2001). For the purpose of this research and the development of a conceptual framework the broad label of behavioural data was chosen to represent this type of data. 
The review of the literature therefore led to the design of a preliminary framework shown in Figure 1. The arrows between the major categories of variable indicate that they interact and influence each other. The sub-categories with arrows pointing to the broad categories indicate that these make up or feed into the broader categories in the framework. This framework was first piloted on fifty-nine postgraduate Information Studies students in Singapore in 1998 (Hepworth, 2001).

Place Figure 1 about here.

Application of the framework led to minor modification of the framework in that it was found to be useful to apply the framework at three levels of abstraction. These were:

- the 'group level', where data was aggregated for the entire community. In other words all the environmental, psychological and behavioural data were brought together indicting the general needs of the community.

- The 'individual level' which focused attention on the information behaviour of individuals within the community. This served to highlight individual differences and the person's information behaviour over time.

- The 'moment of interaction' which drew attention to specific moments when people interacted with a source of information whether it was an information system, such as a database or another person. This highlighted specific problems, challenges or successes associated with their interaction. 


\section{Methodology}

The purpose of this study was to test the framework shown in Figure 1 in a hostile environment. To do this the framework was used to analyse data on a very different community and the data was collected using a methodology that was not connected in any way to the framework. This was Dervin's micro-time line interview (Dervin 1983, 1999). This technique involves asking the interviewee to remember specific situations and identifies information needs, barriers and 'helps' to information access and the impact of information on the individual. The community chosen was informal carers in Leicestershire, UK and this took place in the year 2000.

In the UK informal carers have been defined as people who care for another person(s) for more than 14 hours per week and are not paid for this work. There are an estimated 5.7 million in Britain, with one in six households containing a carer, (Richards and Parker, 1998). Based on national statistics there are an estimated 60,500 adults who provide unpaid care to older people and/or people with disabilities in Leicestershire (The Carers Plan, 2003). The sixty informal carers who were interviewed, using the micro time line methodology, were self-selected from a larger sample of 174 informal carers who had responded to a questionnaire survey. The questionnaire was distributed via two nongovernment orgnisations Council for Voluntary Services (CVS) and Carers of Leicestershire Action Support Project (CLASP), who provide support for informal carers in Leicestershire. CVS distributed 250 to informal carers in North West Leicestershire. CLASP distributed 250 to the Oadby and Wigston district and 500 to Charnwood, Hinkley and Bosworth and Blaby districts of Leicestershire. The individuals chosen were those output from their databases i.e. for CVS the first 250 in that region. Out of the 174 
71\% were between forty and sixty nine years old. Slightly over two thirds were women (68\%). The relationship between the carer and the cared for person was predominantly spouse/partner (47\%) followed by parents caring for children who had a medical condition (29\%) and adults caring for elderly parents (20\%). The cared for person's condition varied widely and many had a number of medical conditions. The most common were stroke (13\%), confusion (13\%), diabetes (7\%), heart disease (7\%) and Alzheimer's disease (6\%). The level of care was high with 62\% stating that they spend over one hundred hours per week in their caring role. Caring involved personal care (such as bathing, washing and dressing), physical help (such as getting up and downstairs, getting in and out of bed), help with paperwork (filling forms, bills, finance etc.), practical help (preparing meals, laundry, talking to doctor, doing shopping etc.), keeping company (sitting with, talking to etc.) (Hepworth et al. 2000).

The sixty interviews were conducted with informal carers in the year 2000. These sixty had stated in the questionnaire that they were willing to be interviewed. They were thus self selected, were literate, and able and motivated enough to fill in a questionnaire. Whereas young carers met during the study found it very difficult to complete the questionnaire due to literacy and attitudinal problems. The sixty were also segmented into three groups at the request of the funder, Leicestershire County Council: carers spending over 100 hours a week in the caring role; carers of people with dementia; young carers. All the interviews were transcribed verbatim and then coded using qualitative data analysis software. The data was categorized using the framework developed in the pilot study. This led to further modification of the framework where it was felt 
appropriate. For example previous categories were put into slightly different clusters and relabeled to better reflect the data content. This was done until all data was effectively categorized.

\section{Findings}

The framework in Figure 1 was used, initially, to organise and analyse the data gathered on informal carers' information experiences. This process led to a change in the organization of sub-categories, and clustering of these sub-categories also led to the relabeling of the broad clusters of data. Roles, norms and tasks were clustered under sociological data. Cognitive knowledge, cognitive process and cognitive ability and style were re-labeled as knowledge state, cognitive state, style state and affective as affective state and clustered under the broad heading of psychological data. The word state was thought to be more appropriate because it represented the transient nature of these states. Data about sources was separated from roles, norms and tasks and subdivided into source character and source behaviour and placed under the broad heading of source data. Separating out sociological data and source data from under the broad heading of environment reflected the importance of source data and its character and behaviour and its impact on behavioural, psychological and sociological data.

The data is presented here using the final conceptualisation of the framework shown in Figure 4. 


\section{Data on informal carers}

The 'group level of analysis' is presented first where all the sociological, psychological, behavioural and source data was aggregated. The group level of analysis gave a composite picture of the psychological, behavioural and source needs of the community as a whole. Addressing these needs would help fulfill the range of information intensive tasks and roles of the target audience.

For each category of data quotations from carers are selected to help indicate what kind of data falls under the various categories. It should be noted that only a small number of quotations for each category are given. However these should be sufficient to indicate to the reader the nature of the categories and the type of data that was gathered. To help reflect on the usefulness of this data for defining the user requirements of the informal carer and their information needs a brief discussion of the implications of this data for information service design is also given.

\section{Sociological data}

Roles, norms and tasks

The role that the informal carers research was concerned with was the role of informal carer. No other aspect of their life was addressed. Norms associated with this role were epitomised by the following quotation:

'I will look after him as long as I can' This norm, although not directly related to information behaviour, has implications for the carer and their information needs. Information, for example, could be provided that discussed these issues and helped the carer set 'normative' boundaries around the role of 
carer. This kind of discussion would lead onto related topics such as respite for the carer and forms of help that may provide some relief for the carer which otherwise may not have been explored due to the acceptance of the overriding norm of selfless unstinting care. In addition, information could be provided that helped with the related interpersonal issues that these norms raise.

A number of tasks were apparent including:

- organising health care related services;

- $\quad$ organising social care such as home help;

- organising financial support to enable caring to take place.

Tasks that were common but not always evident were:

- managing the diet of and in many cases feeding the cared for person

- administering medication

- facilitating the mobility of the cared for person. This often involved manual labour but also included organising a wheel chair, stair lift or taxi

- adapting the accommodation to cater for the cared for person

Less frequent were:

- identifying suitable accommodation

One young carer mentioned 'get her happy because she is always miserable'. This may be a common yet unconscious task. Other tasks such as, filling forms, doing paperwork and washing were also mentioned. 
In terms of user requirements and information provision these tasks need to be supported by information provision. Furthermore the tasks provide one structure that could be used to package and deliver information content. This would have the advantage that carers would recognise the tasks, see the purpose of the information and engage with it rather than being presented with an abstract list of categories of information that they may not relate to their situation.

\section{Psychological data}

Data concerning the psyche or mental state falls under the broad heading of psychological data. As mentioned before this was broken down into knowledge state, cognitive state, style state and affective state. The word state was used to emphasise that this is a condition associated with a situation and the person's response to that situation rather than a permanent condition or state of mind.

\section{Knowledge state}

Informal carers experienced situations where they needed to be knowledgeable, that is, have a certain knowledge state. In each individual's case the knowledge state would vary. New carers for example, generally, 'knew nothing' and had very little understanding of the system, useful organisations or the medical condition. Knowledge states that were identified included the following areas:

- The condition or illness of the cared for person

'it does actually help you it describes the type of seizure, there are different types of seizure so you can identify which type of seizures' 
- Medical terminology

'medication, now that Propolazine call it that, briefly PRN, so unless you know what PRN is she don't know what you are talking about'

- Medication and side effects

'when I found out the side effects what was likely to happen over a period of time, I suppose it did help a lot because I knew what was likely to happen'

- Diet

'I knew that he could eat them and he wasn't going to be ill'

- Organisations

'so obvious now is the CLASP organisation, but it wasn't when you don't know about it'

- Finance

'I didn't know we could have Carers' Allowance'

- Systems

'rules of the game' - how the government's health and social system works including changes that take place, such as, allowances or legislation, but also practical knowledge such as the best time to phone. 'I think that's why we haven't got a social worker because we wouldn't accept the respite care' [incorrect knowledge]

- Equipment 
equipment for the cared for person to enable them to function and participate in life

'I have been told they aren't any good anyway because they have got no back support on them'

Categories and different levels of knowledge required have implications for information provision and would need to be taken into account when providing information.

\section{Cognitive state}

The following cognitive states were identified. These can be seen to be related to the knowledge state of the individual. Cognitive states reflect the thinking processes associated with situations.

The informal carers context

- Uncertainty (a conscious state of unknowing about a situation or topic)

'up to him being eighteen months old I was banging my head against the wall, asking if something's wrong'

- Questioning (specific questions asked)

'I asked him about the fact that her tongue was sticking out'

- Strategic (mental strategies such as 'finding out for oneself', 'taking time to sift information' etc.)

'wanted to look at as many as you could, see which was the best stair lift' 
Cognitive states provide an indication of the questions in the mind of the user and mental strategies they have developed as well as cognitive skills. The category 'uncertainty' reflects the expressed need to want to find out about what is happening now and what will happen in the future. This tended to be represented by 'what if ...' questions which were often associated with severe anxiety. Providing answers to 'what if' questions could help to relieve anxiety. 'Strategies' provide an insight into cognitive strategies that could be encouraged or helped or communicated to other carers, for example, 'juggling people' or 'dealing with instructions' or 'reading about the condition'.

\section{Style state}

Style states were categorised as either negative or positive because the data reflected these opposites and also because negative and positive style states had an impact on information behaviour and becoming informed.

'Positive' style state was represented by statements such as:

'I have always been able to go and find out and ask and not been afraid to do that'

'I am strong enough I think to fight for what I want ... and find out things' 'Negative' style state was represented by statements such as: 'hope that the problem will go away' [early stages] 'scared of the unknown but then you don't really want to know' 
The following negative affective states were associated with certain negative 'style states'.

'just too much'

'why me again'

'rather abandoned at the time'

'it can't be happening really'

An information system should enable and encourage positive style states (since these affect their information behaviour) and information could be provided, quite specifically, to encourage and enable these states. It is also important that information providers are aware of these different style states so that they can adapt their support. Style states are discussed further at the individual level of analysis.

\section{Affective state}

Affective states were also categorised as positive and negative and tended to concern feelings associated with the situation and also with interaction with sources. This data gave an indication of what individuals would like from an information service.

'Positive' affective states included:

'that was brilliant' [people you could talk to ... they were there when you needed them]

'was helpful' [she (occupational therapist) talked to me about things] 'they were very helpful they seem to have certain people who specialised in various aspects of disability' [carers' organisation] 
'I got the information and I read it and I felt happy that I knew about it' 'I feel the more information was given the better you are to deal with things' 'that helped a lot' [read about the condition]

'Negative' affective states fell into the following categories:

- Isolation and victimisation

'you just feel like one in a million'

- Overwhelmed

'Hopeless really, it was upsetting because I didn't know whether it was worth going to anyone about, confused, cause you know you feel like you are doing wrong' [young carer]

- Impact of inadequate help

'he didn't believe me' [doctor] 'why me again'

- Reaction to information that was not wanted

'just horrible’ [possible negative effects of earlier treatment]

'in some respects, we did not want to know answers to some questions'

- The way information is provided and received

'being told he can't do this' [no talk of what he could do]

- Anger

'Not treated as an individual'

'penalised for having money'

- Desire for easy access to information and knowledge 
'to think that there is somebody on the other end of the line that can instantly help you ... it doesn't turn out like that'

'I ought to get somebody on the phone to speak to at this particular time'

The affective state has implications for information services design. For example, a service could take as one of its objectives to help counteract the negative affective states and encourage where possible, through information provision, the resolution or reduction of negative affective states. For example:

Informing people that they are likely to experience such affective states may help them to prepare for them and also let them know that others experience these states and hence are not alone;

$>$ consciously address the issue of isolation by informing people of others in similar situations and facilitating contact;

to present information in such a [positive] way that it can be taken on board and that enables the carer to be become aware of strategies and solutions that may help them and the cared for person thus decreasing the feeling of being overwhelmed.

\section{Behavioural data}

Behavioural data was clearly a type of data that the conceptual framework identified as important.

Information behaviour fell into the following categories:

- Telephone contact with:

Social (social services, non-government organisations)

Health (health service, non-government organisations, independent practitioners) 
Educational services

Police

Equipment suppliers

- Reading

- Visiting

- Consulting

- Sharing

- Educating

Using the telephone to contact services was the most common behaviour. This means of remote communication is likely to be important because of the difficulty many carers have in leaving the home. The immediacy of telephone contact was seen as important. An effective method to access services for carers from the home, is therefore, seen to be important.

The majority of carers read books, leaflets etc. 'look the information up in books' [about the medical condition]. One carer went to great lengths to find material using a contact in the hospital to source medical books. However, the language used and the level of detail was often inappropriate. There was a need for medical information that was appropriate for people with little medical knowledge.

'Visiting places' was associated with a range of situations where individuals specifically wanted to be informed. For example:

'I went along to a meeting' [carers group] 
'we went' [to mobility exhibition]

'joined all the long queues and sat and waited and didn't seem to get much information' [benefits office]

'I ask at the GP' [about medical condition]

In some cases there was a need to see a place where the cared for person was going for a period of time such as a respite centres. In these situations it was extremely important for the carer to make sure that these places were appropriate. Virtual tours, assuming people had access to the appropriate technology, could help the carer to at least get a first impression of the location and the services provided, particularly if it was supplemented with the views of other people.

'Consulting' outside the home tended to be with experts, particularly in the medical area, but also with welfare and educational services and staff in non-government organisations. The opportunity to have these dialogues with 'experts', from the home, would be generally beneficial, perhaps via video phone, especially where the mobility of the carer or the cared for person was problematic.

'Sharing' refers to the sharing of data, information and knowledge informally between carers and other people (other carers, neighbours, relatives etc.), 'I did get some information from other visitors'. As noted earlier this was seen as an excellent way of becoming informed, particularly where others were having or had had similar experiences. There is therefore an obvious opportunity for an information service to 
facilitate this sharing. However, as one carer pointed out, the information exchanged in this way needs to be vetted.

'Getting equipment' was relatively common, for example, 'we just went and bought this bath seat'. Finding out about equipment ('tracking something down'), viewing or trying out equipment was not easy.

'Educating' was cited by one adult carer and three young carers. It is interesting to note that Bruce (1995), when discussing various levels of information literacy, associated this kind of activity with an advanced stage of information literacy. Carers had reached a point where they were educating others about carers. The young carers, for example, had been involved in presenting to doctors and informing them of the role of young carers. Helping carers to communicate with other people about their situation could be a feature of a user-centred information service. Such a service would regularly facilitate the sharing of knowledge between all stakeholders involved with such a community including the carers themselves.

\section{Source data}

As mentioned above source data was treated as separate category in this framework and the concepts of source behaviour and source character were introduced (see Figure 2) because the data reflected this distinction. Source behaviour and source character were found to be significant and helped to identify negative and positive source attributes that also helped to identify strengths and weaknesses of current sources and indicated 
solutions. Some sources, such as the Alzheimer's society, played a key role in helping people to navigate the information sources such as identifying other organizations and helping to complete forms that enabled access to services. The character and behaviour of a source had an effect on the individual's psyche and the fulfillment of tasks.

Sources that carers interacted with were as follows:

- Organisations

Government

Non-government

Commercial

- People

Health service professionals

Social service professionals

Social benefit professionals

Commercial service providers (transport, pharmacist etc.)

Non-governmental organisation staff

Carers

- Information objects

Books

Leaflets

Directories

Newspapers

Television 
Radio

Forms

Prescriptions

- Equipment

Mobility aids

Medical aids

Other specific aids e.g. for eating

- Services (in the home)

Home help

Meals on wheels

Occupational therapy

Medical service e.g. nursing

- Services (hospital)

- Financial e.g. allowances (attendance, mobility, council tax etc.)

It can be seen that carers as a group come into contact with and need to know about a wide range of sources. Equipment was included because sources of information about equipment were important to the carer. Similarly people required information about services including their function, services they offer, roles and how to instigate services. Many of the carers did not know about these when they started caring, and were unsure about the function of these sources. Some were specific to carers caring for someone with a particular condition. Others were relevant to all carers. Some were relevant to carers at specific points in time. Building up a mental map of this information landscape 
was not easy for the carer and developed over time, generally with the assistance of other people who were familiar with the environment.

An information service for informal carers would need to enable people to map and navigate these sources showing the relevant information objects as well as relevant organisations, their role, the function of their staff and the services they provide and how they can be contacted. Currently guides do exist to services and equipment. However they need to be made more easily accessible in the home and to be adaptive to the situation of the enquirer.

Encapsulating many of the positive attributes of a source is 'the person in a similar situation', 'you have really got to talk to someone who has been through it', who has knowledge that can be applied directly to the situation of the carer needing information.

\section{Source character}

Source character relates to those attributes of an information service that imply the style of user-service interaction. Each attribute could be applied to any medium including face to face, paper based or electronic. The positive attributes (of source character) that were associated with a 'good' information service for carers included:

- Accessible

'I phoned them up, you didn't need to be referred by somebody, you could ring up 
yourself. So I phoned them up and asked them if they would do that, and they came over and assessed me and said 'yes'

- Knowledgeable

'they know all the volunteers etc. in the city and the county and they know all the places'

- Listen

'you could talk to them about anything, and they like listen'

- Good manner

'seemed sort of personally interested'

- Proactive

'if she doesn't know she will go and find it like straight away'

- Information provider

'he will give us everything you need to know, and tell you where to go,

recommendations ... he will discuss with you what medications are available, what's new, what do you think will work'

- Responsive

'she will get back to me'

It may seem strange to apply these criteria to paper or electronic information services. However, even a paper-based service can be ‘accessible’. 'Knowledgeable’ may seem obvious, but it was apparent that current service providers were, in some cases, not knowledgeable about their own services or about other services and needed support. Because it was difficult for carers to access services it was important that the contact they 
had was knowledgeable and informative. The irritation of dealing with people who lacked knowledge was made clear by the following quotations:

'I mean I knew more ... she couldn't even open one' (wheelchair) ... if someone had been there to totally tell you about things from start to finish' and [they were] 'barely out of nappies ... (they) haven't got a bloody clue about hands on handling the situation'.

'Listens' may be an inappropriate category for print, however, printed material should provide directional information to services where people will 'listen'. Electronic services could facilitate access to experts or professionals who can 'listen'. In addition, technology could facilitate access to other carers.

The impact of the characteristic 'proactive' is less clear but has implications for the availability and the possibility of providing carers with information in the house when appropriate or when new information becomes available.

'Manner' was an important criteria, in relation to how people interacted with the carer. The abrupt, remote manner of several consultants and the patronising character of some health professionals, epitomises inappropriate character.

'Responsiveness' again has implications for information service provision. For example, if a facility offered a question and answer service it would be responsive. This may seem ambitious but, as NHS Direct (NHS Direct, 2003) has shown, a service of this kind is possible. 
Negative attributes, such as, 'poor information provision', 'complexity of information’ and 'information overload' drew attention to information that was too complex to understand.

\section{Source behaviour}

Source behaviour relates to how the source responded to the user as a result of interaction. Positive attributes of source behaviour were characterised by respondents as:

- Enabling contact with other 'artifacts'

'she put me in touch with so many people'

- Contact in the home

'she actually came round the next day and ... took me up to school'

- Information provision

'she gave me a this book here to help and in there was all the information I've ever wished for and I got their name from there'

- Form filler

'did a lot of paperwork, in fact she sent most of the forms in for me'

- Facilitated financial help

'he helped find the money'

- General services (such as helping with day to day tasks)

'they (Occupational Therapist) look around the house to see what other things that is going that they could help you with' 
'Enabling contact with other artifacts' was found to be a crucial role of services. In particular those agencies that were able to facilitate contact with organisations and services across sector boundaries, such as between health, social and voluntary sectors. Conversely, the partisan nature of information provision, where organisations tend to only provide information on their services proved to be a barrier to information access.

‘Provider of information' was a common description given to a good service provider and referred to features such as 'discussing', 'giving print' (leaflets etc.), 'drawing attention to services', 'finding out', 'showing how to apply', demonstrating the demand and need for information provision.

'Form filler', often associated with 'making contact', was a common positive attribute given to a service provider by carers. An information service for carers would need to provide advice and help on the filling in of forms and enable access to appropriate forms.

Direct 'financial help' from non-state bodies was rare and limited to charities, the church and in one case a previous employer. Judging from the frequency of this type of data, knowing how to get access to sources of finance was one of the most important areas of knowledge required by carers (after medical knowledge).

'General services', tended to concern day to day tasks, a wide range of services was identified including: gardening, laundry, shopping, a trip out. An information service 
would need to enable access to such services. Practical advice was also needed on how to conduct tasks such as giving medication.

The 'individual level of analysis' was concerned with understanding the individuals' experience. This level of analysis helped place data in context i.e. what took place over time and how one thing affected another. At the individual level of analysis it was evident how people built up a map of their environment and knowledge about the subject domain and the likely chain of events (see Figure 2). This provided an indication of what the carer may need to know and when. The early stages of the mapped scenarios, for example, indicated a pressing need for an explanation of what exactly is wrong with the cared for person. Later this led to the need to understand the prognosis and what is likely to happen so that the carer could prepare psychologically and practically.

It was also possible to identify broad differences in individual behaviour. In particular the effect of different style states. These findings conformed to those of Miller and Mangan, (1989), and Baker, (1995), and their description of 'monitors' and 'blunters'. These distinctions are important. An information provider could identify people who may be less likely to seek out information and are hence more dependent on the provider. Secondly it may be possible to present information in a way that is more appropriate to this group.

In Figure 2 a person, who conforms to what I have called a 'positive style state', can be seen to be proactive , contacting number of organisations for help which led to learning 
and action. People who tended to conform to a 'negative style state' tended to have fewer contacts, took far longer to make useful contacts and tended to depend on others to navigate the source environment for them. The affective data, associated with negative style states, also tended to be negative. A combination of these factors meant that such people suffered severe stress and difficulty for several years when, in fact, help was available. The latter group is therefore particularly vulnerable and the information provider would need to go to extra lengths to ensure that these people were getting access to information.

The individual level of interaction therefore drew attention to how people learn, over time, and the context within which specific information interactions take place. This is a view that is lost at the group level when one generalises needs across the community and also when focusing on specific moments of interaction.

Figure 2, showing the individual level of analysis, indicates how the different types of data are associated with each other. Interaction between the respondent and sources can be seen to lead to changes in knowledge, cognitive and affective states. 
Place Figure 2 about here

The third level of analysis was the 'moment of interaction'. This was distinguished from the above two levels of analysis in that it concentrated attention on specific problems and needs associated with interaction with sources. Analysing data at this level is similar to studies of usability and human computer interaction. In the case of the carers it enabled one to identify positive and negative interactions with sources.

Place Figure 3 about here

In this example the carer met with the person in the welfare rights orgnisation. The benefits of information interaction, from this contact, are evident. Analysis, at this level, helped to recognise the 'interface' and 'functionality' associated with sources and their benefits. Due to the nature of data collection, i.e. an interview rather than observation, the amount of detail on moments of interaction was sparse because the verbal descriptions of past events were simplified.

\section{Discussion}

The framework provided a useful guide for analysing and organising data that concerned the information experience of a group of people who needed information, in this case the informal carers. 
Figure 4 shows the main categories and sub-categories of data in the framework and their interaction. As shown above this framework can be applied at three levels of analysis, 'the group level', 'the individual level' and 'the moment of interaction'.

Place Figure 4 about here

With regard to earlier frameworks of information behaviour and the information retrieval process similarities are evident particularly with Wilson's 1996 framework (Wilson 1999) and Ingwersen's (1996) framework. Both frameworks highlight the importance of similar categories of data, whereas others focus on a sub-set. However, the framework developed here helps to further explain the 'person-in-context' concept in terms of roles, norms and tasks. Intervening variables are broken down further, in fact all categories are seen as intervening, and psychological factors are clearly distinguished and clustered. Wilson’s ‘activating mechanisms’ and passive/active search are categorized under psychological data under style state and cognitive state and are seen to be both negative and positive. The importance of style state was emphasized and that this may be a barrier to information access. The negative effect of lack of information on the affective state was also highlighted in this study. The notion of levels of analysis, (moment of interaction, individual level of analysis, group level of analysis), is supported by Wilson and his 'nested model' and also by Hert (1997) who distinguished between the wider information seeking process and interaction with the 'system'. Few other authors seem to recognise these differences. However, Wilson uses different labels: information 
behaviour, information seeking behaviour and information search behaviour that, it could be argued, make the distinction between levels of analysis less clear. Earlier studies can be seen to fall under one or more of these levels of analysis. For example, Spink's (1997) and Saracevic's (1996) models can be seen to operate at the moment of interaction. Knowing which level of analysis one is working at clarifies what one is studying. This in turn influences the choice of research techniques. Ingwersen's (1996) model primarily relates to understanding the moment of interaction with the information system rather than defining the information needs of a community. Ingwersen's concept 'current cognitive state' is sub-divided under psychological data.

The importance of sources was given greater prominence in the framework developed in this study and the distinction between source character and source behaviour found to be useful. This was because these categories of data gave a clear indication of the kind of interaction the user would like with an information service.

\section{Conclusion}

The framework complements and builds on previous models and is useful in terms of:

- Highlighting the importance of types of data that one should collect to understand information needs and requirements;

- Confirming the importance of previous research into factors/variables that effect the information experience;

- Integrating, refining and ordering factors identified by previous researchers that are important for understanding the information experience of people. 
- Enabling a rich picture to be generated of the information experience of the target community and helping to specify solutions.

\section{Limitations}

Due to the self-selecting nature of the respondents it was not possible to state that the information needs identified in this study are representative of the whole population. However, the findings do reflect those of other researchers and in fact provide more detail (Wollin et al. 1999, 2000). Depending on the micro time line interview technique to gather data did impose some limitations. Choosing a range of techniques to elicit data, such as task analysis to specifically identify tasks and sub-tasks, would probably have provided more comprehensive data on the various parts of the framework. Furthermore using the micro-time line interview meant that data was gathered on the most memorable or significant situations that carers could recall, which is one of the strengths of this technique. However, this meant that smaller events and the more day-to-day tasks and the associated information needs were probably underrepresented.

To gather more data on moments of interaction some form of observation would also have been useful, such as spending time with the respondent or using techniques such audio-diarying and video-diarying to capture data on day to day experiences and interactions. A subsequent study of the information needs of people with multiple sclerosis found audio-diarying very effective for gathering data at this level of detail (Hepworth et al. 2003). This would also have led to more data on cognitive states, particularly if concurrent talk-through techniques were used to capture thoughts while the 
carers undertook tasks. The behavioural data would also have been more detailed if some form of logging of behaviour, over time, had taken place. Nevertheless, sufficient data was gathered to demonstrate the usefulness of the various categories of data in the framework.

Further research is required to test the usefulness of the framework in different contexts. It would probably be beneficial to develop and incorporate research methodologies that were specifically suited to gathering the various types of data, although the micro-time line technique provides a very robust tool. The framework also identified a number of intersections between different types of data. These deserve further study. A recent example of such work is Heinstrom's (2003) study of the impact of personality types on information behaviour. Other areas deserve further study, for example, the relationship between certain knowledge or cognitive states and behaviour or whether a specific affective or style state requires a certain type of source character and source behaviour. The latter, for example, may lead to a better understanding of how to present information in a way that would attract the person who demonstrates 'blunter' characteristics.

The interplay between different factors associated with the information experience can be seen to be complex and is still, I would argue, only crudely understood. There is therefore ample scope for further empirical studies that explore the relationships between the different variables that were shown to be significant in the conceptual framework developed as a result of this study. 


\section{Acknowledgements}

I would like to thank the informal carers for agreeing to share their experience;

Leicestershire Social Services for funding the carers study; and Frank Odhiambo (Research Associate), Joan Powell (interviewer) and Janet Harrison (carers project partner) for helping to collect data. I would also like to thank the reviewers for their helpful comments. 
References

Allen, B. In Williams, M. (ed.) (1991). Cognitive research in Information Science: implications for design. Annual review of Information Science and Technology (ARIST), 26, Medford, NJ: Learned Information, 3-37

Baker, L. (1995). A new method for studying patient information needs and information seeking patterns. Topics in health information management, 16(2), 19-28

Belkin, N. (1994). Design Principles for Electronic Textual Resources: Investigation Users and Uses of Scholarly Information. In Zampolli, A. Calzolari, N. Palmer, H. (eds.) Current Issues in Computational Linguistics: In Honour of Don Walker. New York: Giardini \& Kluwer, 325-344

Bruce, C. (1995). Information literacy: a framework for higher education. The Australian Library Journal, 44(3), 158-170

Case, D. (2002). Looking for information: survey of research on information seeking, needs, and behaviour. San Diego: Academic Press

Cheuk, B. W. (1997). An experienced based information literacy model in the workplace: Case studies from Singapore. In Information literacy: The professional issue. Proceedings of the third national literacy conference. Adelaide: University of South Australia Library, 74-82. 
Choo, Chun Wei. (1994). Perception and use of information sources by Chief Executives in environmental scanning. Library and Information Science Research, 16(1), 23-40

Dervin, B. (1983). An overview of sense-making research: concepts, methods and results to date. Paper presented at International Communication Association Annual Meeting, May, Dallas, Texas, May, 1983. Found at http://communication.sbs.ohiostate.edu/sense-making/art/artdervin83.html [14/01/03]

Dervin, B. (1999). On studying information seeking methodologically: the implications of connecting metatheory to method. Information Processing and Management, 35(6), $727-750$

Ellis, D. (1989). A behavioural approach to information retrieval design. Journal of Documentation, 45(3), 171-212

Ford, N. Wood, D. Walsh, C. (1993). Cognitive styles and online searching. Information Research News, 4(1), 6-13

Heinstrom, J. (2003). Five personality dimensions and their influence on information behaviour. Information Research, 9(1) paper 165. Found at http://InformationR,net/ir/91/paper165.htm [17/10/03] 
Hepworth, M. (2001). Situations experienced by students when searching for information on an unfamiliar topic: implications for system design and user support. Found at http://www.online-information.co.uk/proceedings/online/2001/hepworth_m.asp $[14 / 01 / 02]$

Hepworth, M. Odhiambo, F. Harrison, J. (2000). Informal carers report. Loughborough: Department of Information Science, Loughborough University

Hepworth, M. (2002). A conceptual framework for understanding people's requirements for an information service. Unpublished $\mathrm{PhD}$ thesis. Sheffield: Sheffield University

Hepworth, M. Harrison, J. James, N. (2003). The information needs of people with multiple sclerosis. In Proceedings of the Eight International Symposium on Health Information Management Research. 1-3 June 2003. Borås, Sweden,142-159

Hert, C. (1997). Understanding information retrieval interactions: theoretical and practical implications. Greenwich, CT: Ablex.

Ingwersen, P. (1996). Cognitive perspectives of information retrieval interaction: elements of a cognitive IR theory. Journal of Documentation, 52(1), 3-50

Krikelas, J. (1983). Information seeking behaviour: patterns and concepts. Drexel Library Quarterly, 19(2), 5-20 
Kuhlthau, C. (1991). Inside the search process: Information Seeking from the User's Perspective. Journal of the American Society of Information Science, 42(5), 361-371

Kuhlthau, C. (1997). The influence of uncertainty on the information seeking behaviour of a securities analyst. In Vakkari, P. Savolainem, R. and Dervin, B. (eds.) Information seeking in context: proceedings of an international conference on research in information needs, seeking and use in different contexts, 14-16 August, 1996, Tampere, Finland. London:Taylor Graham, 268-274

Leckie, G. Pettigrew, K. Sylvain, c. (1996). Modeling the information seeking of professionals: a general model derived from research on engineers, health care professionals and lawyers. Library Quarterly, 66(2), 161-193

Line, M. (1971). The information uses and needs of social scientists: an overview of INFROSS. Aslib Proceedings, 23(3), 412-434

Marchionini, G. (1995). Information seeking in electronic environments. Cambridge: Cambridge University Press

Miller, S. Mangan, C. (1983). Interesting effects of information and coping style in adapting to gynaecological stress: should a doctor tell all? Journal of personality and social psychology, 45 (1), 223-236 
NHS Direct (2003). Welcome to NHS Direct Online. Found at http://www.nhsdirect.nhs.uk/ [03/03/03]

Nicholas, D. (2000). Assessing information needs: tools, techniques and concepts for the Internet age. London: Aslib

Patmore, J. Mahoney, L. (2003). Internet usability. In Clarkson, P. Coleman, R. Keates, S. and Lebbon, C. (eds) Inclusive design: design for the whole population. London: Springer Verlag,

Richards, D Parker, G. (1998). Informal carers: results of an independent study carried out on behalf of the Department of Health as part of the 1995 General Household Survey. London: The Stationery Office

Saracevic, T. (1996). Modelling interaction in information retrieval (IR): a review and proposal. In Hardin, S. ed. $59^{\text {th }}$ Annual Meeting of the American Society for Information Science. Silver Spring, MD: American Society for Information Science, 3-9

Solomon, P. (1997). Discovering information behaviour in sense-making. I. Time and timing. Journal of the American Society for Information Science, 48(12), 1097-1108 
Spink, A. (1997). Study of interactive feedback during mediated information retrieval. Journal of the American Society for Information Science, 48(3), 382-394

Spink, A. Bateman, J. Jansen, B. (1998). Searching heterogeneous collections on the Web: Behaviour of Excite users. Information research, 4(2). Found at http://informationr.net/ir/4-2/pepers53.html [13/01/02]

Spink, A. Wolfram, D. Jansen, B. Saracevic, T. (2001). Searching the Web: the public and their queries. Journal of the American Society of Information Science and Technology, 52(3), 226-234

The Carers Plan: 2002-2005. Leicestershire Social Services. Found at http://www.leics.gov.uk/social_services/plans_and_charters/carers/appendix_c.htm $[18 / 10 / 03]$

Vakkari, P. (1998). Growth of theories on information seeking: an analysis of growth of a theoretical research program on the relation between task complexity and information seeking. Information processing\& management, 34(2/3), 361-382

Wilson, T. Streatfield, D. Mullins, C. (1979). Information Needs in Local Authority Social Services Departments: A Second Report on Project INISS. Journal of Documentation, 35(2), 120-136 
Wilson, T. (1999). Models in information behaviour research. Journal of Documentation, 55(3), 249-270

Wollin, J. Reiher, C. Spencer, N. Madl, R. Nutter, H. (1999). Caregiver burden: meeting the needs of people who support the person with multiple sclerosis. International Journal of MS Care, 1(2). Found at http://mscare.com/b9912/page_06.htm [30/06/03]

Wollin, J. Dale, H. Spenser, N. Walsh, a. (2000). What people with newly diagnosed MS (and their families and friends) need to know. International Journal of MS Care, 2(3). Found at http://www.mscare.com/a0009/page 04.htm [30/06/03] 
Figure 1: Initial framework

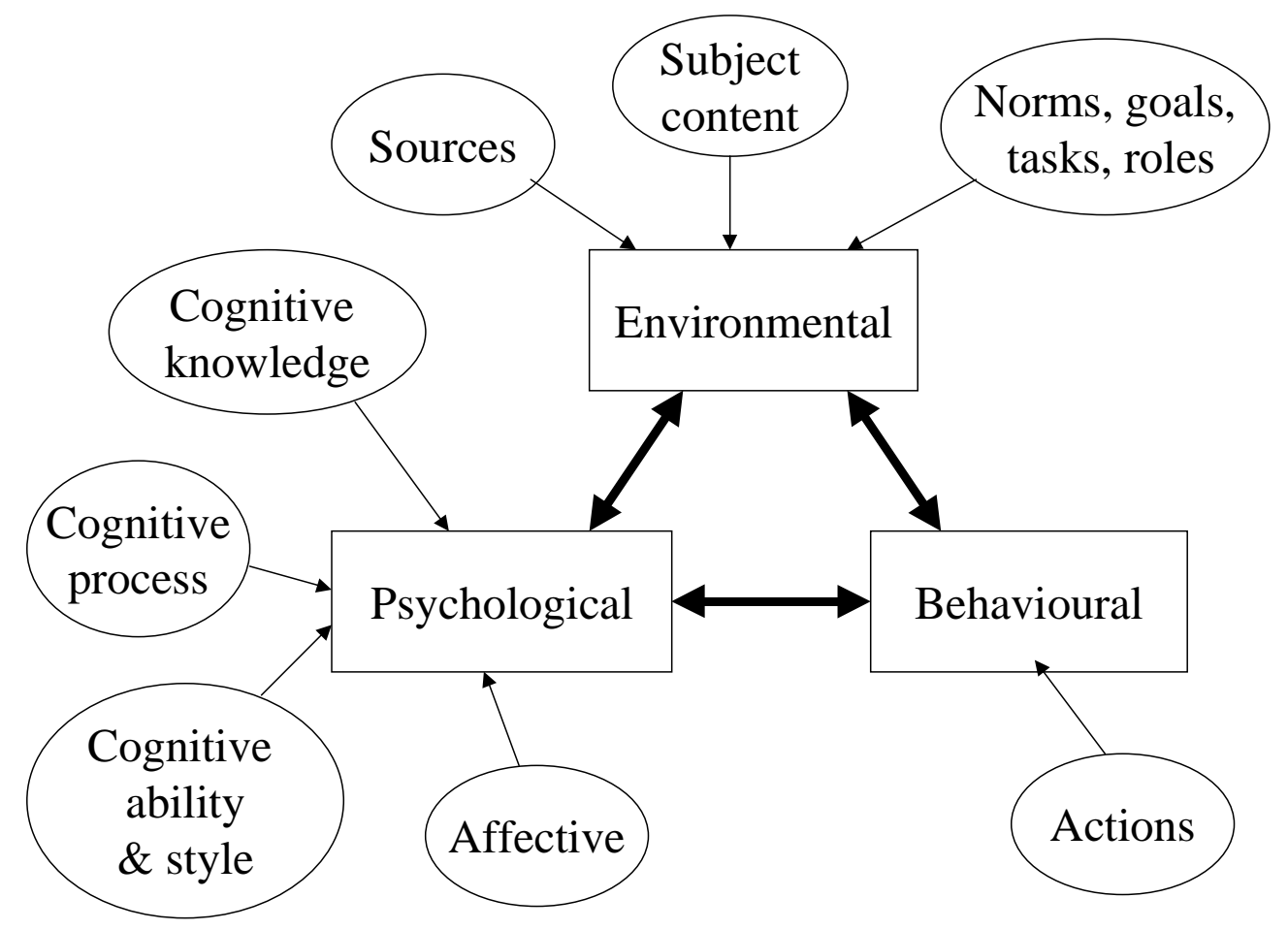


Figure 2: An example of a positive style state

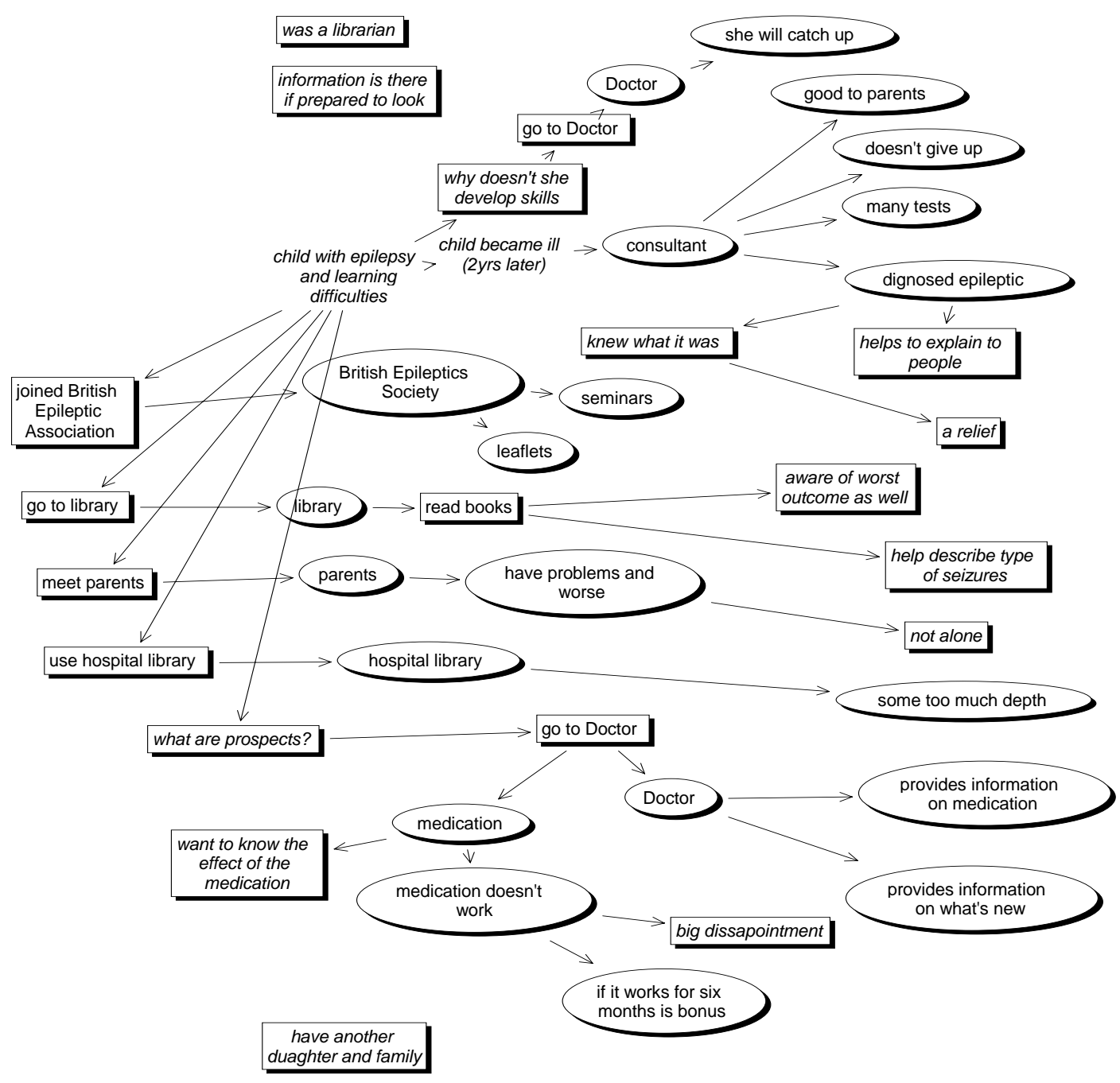


Figure 3: A moment of interaction

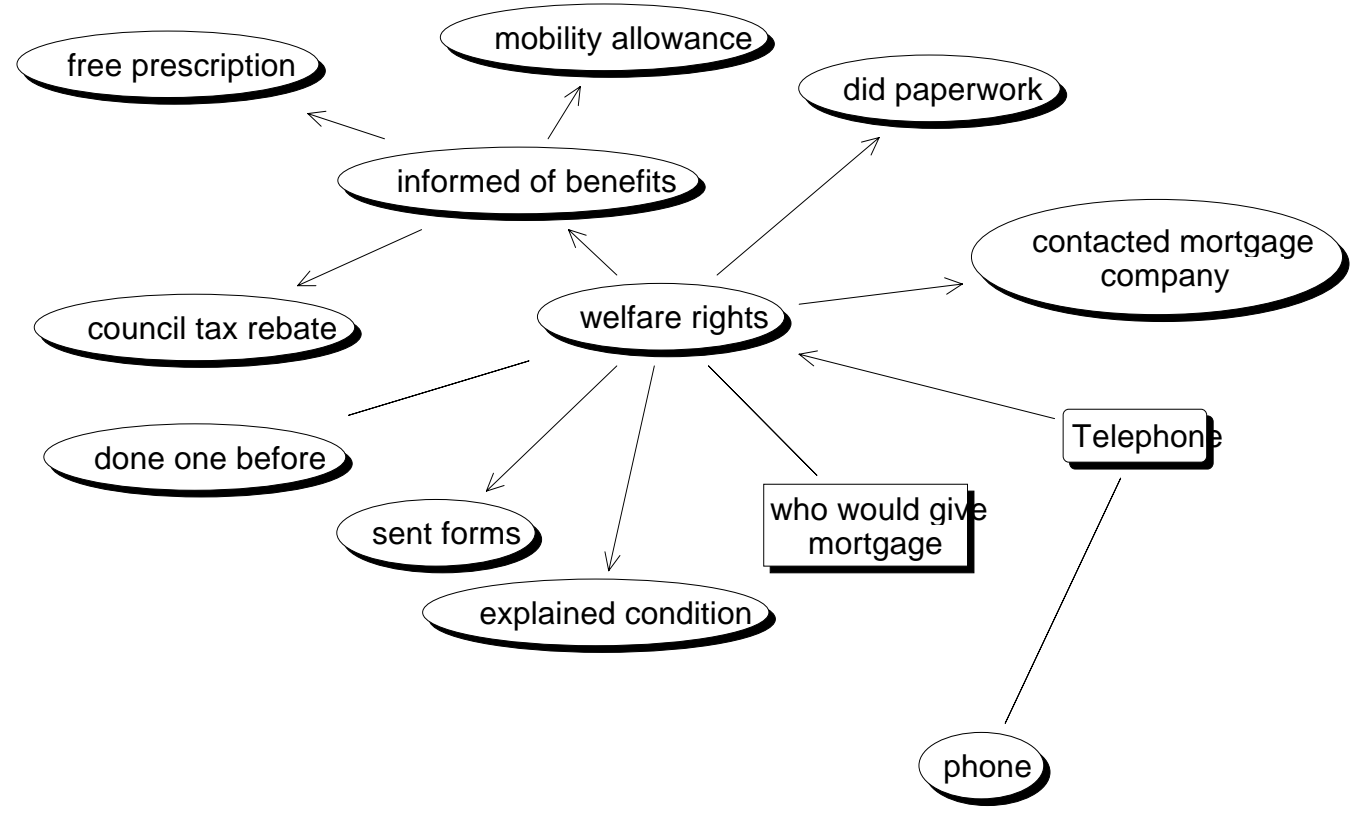


Figure 4: Final conceptual framework

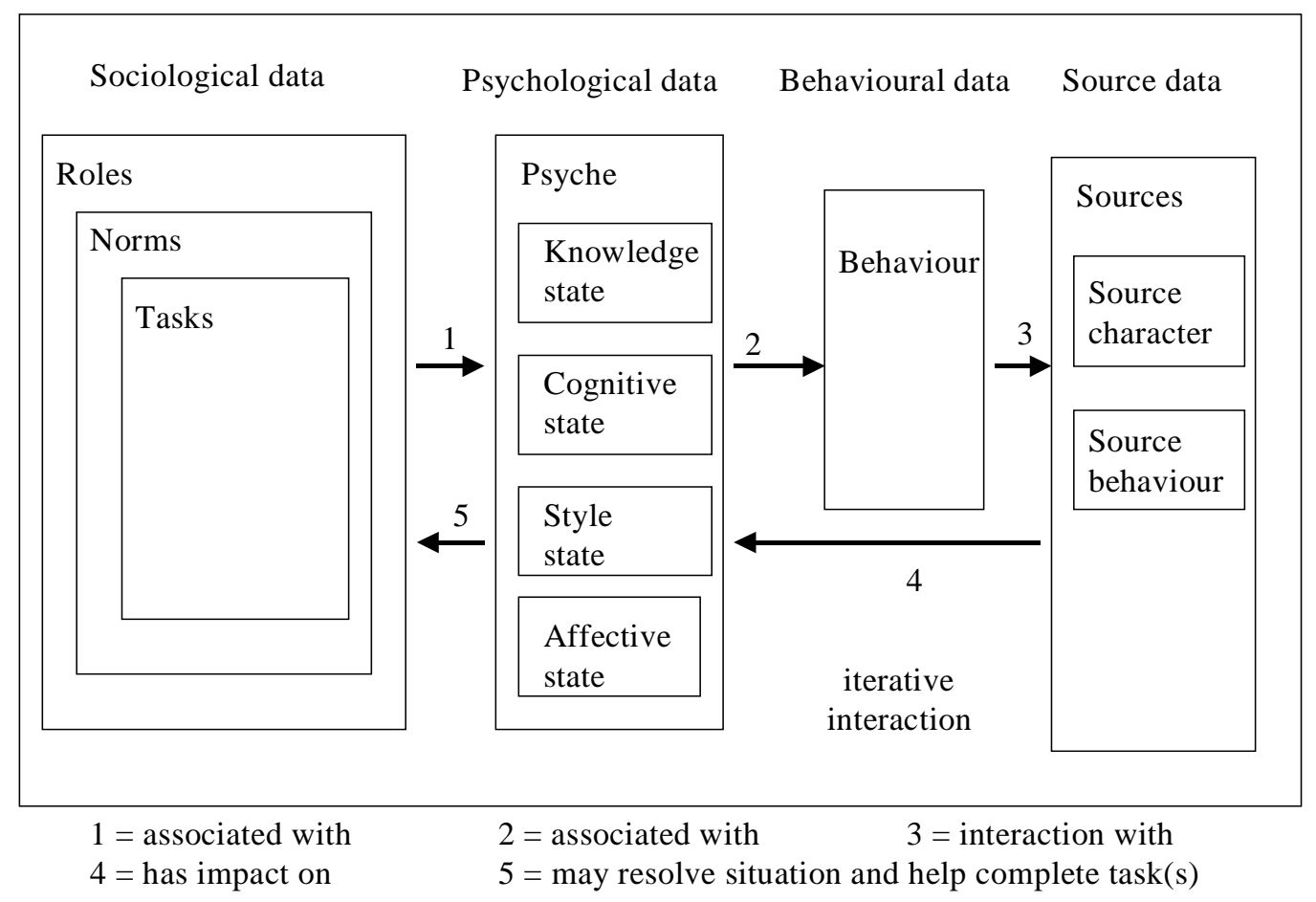

